Brit. J. industr. Med., 1950, 7, 122.

\title{
THE TOXICITY OF METHYL IODIDE: I. PRELIMINARY SURVEY
}

\author{
BY \\ MONAMY BUCKELL \\ From the Department for Research in Industrial Medicine (Medical \\ Research Council), the London Hospital
}

(RECEIVED FOR PUBLICATION MAY 6, 1950)

The proposed use of methyl iodide in fire extinguishers led the Joint Fire Research Organization of the Department of Scientific and Industrial Research to ask the Department for Research in Industrial Medicine (Medical Research Council) to investigate the physiological effects of this substance. In 1948 Ellis described methyl iodide as a pleasant, harmless liquid that was non-toxic, a statement which seemed doubtful in the light of our knowledge of the chloride and bromide. This preliminary report has been prepared because of the growing interest in methyl iodide, and the corresponding need for information on its toxicity.

A search of the literature revealed very little. Two clinical cases of methyl iodide poisoning have been reported, one by Jaquet (1901) and one by Garland and Camps (1945). On the experimental toxicity of methyl iodide there appears to be no recent work. Bachem (1927), using mice, investigated the lethal and tolerated concentrations of methyl iodide and bromide and of ethyl iodide and bromide. According to von Oettingen (1937) he found the methyl compounds to be more toxic than the ethyl, and the iodides than the bromides.

Methyl iodide is a colourless liquid with a sweet etheral odour (mp. $-66 \cdot 45^{\circ} \mathrm{C}$., b.p. $42 \cdot 4^{\circ} \mathrm{C} .(760 \mathrm{~mm}$.) sp. gr. $3 \cdot 325$, and solubility in water at $20^{\circ} \mathrm{C}$., $1.4 \%$ ). It is completely miscible with alcohol. On exposure to air a light brown colour develops owing to iodine being liberated. It is prepared by the interaction of dimethyl sulphate and sodium iodide in a still, the methyl iodide being collected over water or in a closed form of apparatus. Methyl iodide is used in the laboratory as a methylating agent, and it has also been used in petrography. It is used as an intermediate in the chemical industry.

The present communication describes the estimation of methyl iodide in the atmosphere, and experiments on the lethal concentrations for rats and mice. In a paper to be published later the effect of thiol compounds on methyl iodide intoxication and its toxicity compared to that of methyl bromide will be described.

\section{Description of the Experiments}

Estimation of Methyl Iodide in the Atmosphere.In the inhalation experiments the amount of methyl iodide present in the atmosphere to which the animals were exposed was determined by trapping it in alcoholic potash, hydrolyzing, and estimating the liberated iodine with a Volhard titration. This gave the total amount of iodine present, which was assumed to be all in the form of methyl iodide.

One to 10 litres, depending on the expected concentration of the atmosphere to be tested, were slowly aspirated through $20 \mathrm{ml}$. of alcoholic potash $(10 \mathrm{~g}$. $\mathrm{KOH}$ refluxed with $100 \mathrm{ml}$. industrial spirit) contained in a glass bubbler with a sintered glass disc on the inlet tube. The bubbler was cooled to about $-5^{\circ} \mathrm{C}$. with an ice and salt freezing mixture. Using this very slow flow rate and cooled bubbler it was found, using bubblers in series, that more than $95 \%$ of the methyl iodide was retained in the first bubbler, and so only one bubbler was used in subsequent determinations.

Inhalation of Methyl Iodide by Mice.-The experiments were carried out using male white mice, weighing $25 \mathrm{~g}$. each, from a homogeneous stock. During the exposure the animals were caged separately in small wire-mesh boxes which were placed in a glass aquarium tank of 39-litre capacity. The tank was closed by means of a glass plate sealed on with vaseline, and the plate had a hole at each end with a rubber bung in it through which passed a glass tube provided with a tap. The outlet tube was connected to a pump so that the tank could be exhausted to the outside atmosphere by a tube through the window. A measured quantity of methyl iodide was introduced into the tank by lowering the pressure a little by means of the pump and then sucking the liquid from the pipette into the tank by placing the tip of the pipette in the inlet tube and opening the tap.

Concentrations ranging from 85 to $0.5 \mathrm{mg}$. methyl iodide per litre were used. At $85 \mathrm{mg}$. per litre the animals showed obvious signs of irritation, increased general activity, scratching, and running of the eyes. After 15 minutes' exposure all five animals were just conscious 
but very drowsy, by 25 minutes all had lost consciousness, and by 1 hour 25 minutes all were dead.

After 10 minutes' exposure at $50 \mathrm{mg}$. per litre the animals were very drowsy on removal from the chamber, and consciousness was lost about 30 minutes later and not regained. At $25 \mathrm{mg}$. per litre there were still signs of general discomfort and running of the eyes. On removal from the chamber after 10 minutes 'exposure the animals appeared normal, except for running of the eyes, but all died within the next 24 hours.

At the lower concentrations there was a time lag between exposure to methyl iodide and the onset of any effects. At $5 \mathrm{mg}$. per litre the animals were a little drowsy but revived quickly in the fresh air and showed activity an hour later; however, all were dead by the next morning. At this concentration eye irritation was seen only in a few animals.

For the longer exposure experiments a larger chamber ( 1 cubic metre) was used, a measured amount of methyl iodide was introduced, and samples of air removed for analysis as described above. Inhalation of $1 \mathrm{mg}$. per litre produced death after repeated daily exposures totalling from 11 to 43 hours. At $0.5 \mathrm{mg}$. per litre all animals appeared normal after a total of 125 hours in 20 exposures spread out over 30 days, and had gained weight equally with the controls.

After the preliminary experiments to find the approximate toxic level the $50 \%$ lethal exposure time at a concentration of $5 \mathrm{mg}$. methyl iodide per litre was determined in order to have a measure of the toxicity of the compound to compare with a similar experiment to be done on methyl bromide. Groups of ten mice each were exposed to a concentration of $5 \mathrm{mg}$. per litre for varying times, and then observed for a week. The probit of percentage mortality was plotted against log time and a straight line obtained. From this the exposure time to kill $50 \%$ animals at $5 \mathrm{mg}$. per litre was 57 minutes, mortality being 0 at 20 minutes and $100 \%$ at 80 minutes.

Approximate Lethal Dose by Subcutaneous and Oral Administration.-The approximate lethal dose by Deichmann's method was determined for the two methods of administration, and was found in both cases to be $0.15-0.22 \mathrm{mg}$. per $\mathrm{kg}$. body weight. The compound was given as a $10 \%$ solution by weight in arachis oil. For the oral administration the rats were starved for 18 hours before dosing by stomach tube.

Oral Administration of Lower Doses of Methyl Iodide.Young growing rats were dosed daily with methyl iodide in arachis oil, and the growth curves plotted. At $100-200 \mathrm{mg}$. per kg. body weight growth was at the same rate as in the controls. At $300 \mathrm{mg}$. per $\mathrm{kg}$. body weight, two out of six animals showed a temporary check in growth which was recovered by the end of five days. At $500 \mathrm{mg}$. per $\mathrm{kg}$. the growth was considerably less than in the controls. Animals from the $300 \mathrm{mg}$. group were sacrificed after 43 doses given over a period of 71 days, and liver, kidney, heart, lung, and gut were sectioned.

Histological examination of tissues from the inhalation and feeding experiments showed comparatively little pathological change. In the mice receiving a lethal exposure to $5 \mathrm{mg}$. methyl iodide per litre there was acute pulmonary congestion. Renal changes consisting of degeneration of the tubular epithelium with the presence of numerous eosinophilous casts were seen in the mice exposed daily to $1 \mathrm{mg}$. of methyl iodide per litre.

Effect of Methyl Iodide on the Skin.-Methyl iodide, $1 \mathrm{ml}$., was applied to the shaved skin of each of four rats, and it produced no effect. The experiment was repeated with a gauze pad $1 \mathrm{~cm}$. square soaked in methyl iodide and held in place for half an hour with an "elastoplast" dressing. A slight reddening of the shaved skin was produced. A similar pad applied to the human forearm produced a stinging sensation in 10 minutes and at the end of this time the pad was removed, and a slight reddening was seen, which had almost subsided at the end of half an hour. Six hours after the application an erythematous patch about five times the area of the original application had developed. It included three small raised areas. After washing the skin with hot water 19 hours after the application, small vesicles resembling those produced by mustard gas developed on the raised areas. Methyl iodide applied to the forearm and allowed to evaporate freely produced no effect.

\section{Discussion}

Methyl bromide and methyl iodide are both inhibitors of petrol fires. Nicholson (1948) gives the minimum extinguishing concentration of methyl bromide, methyl iodide, and carbon tetrachloride as $0.19,0.28$, and $0.33 \mathrm{~g}$. of compound per litre of air respectively. He states that methyl iodide would appear to be of the same order of toxicity as carbon tetrachloride.

All the experiments reported in this paper were of a pilot nature, and were made using animals singly or in small groups. If larger groups were used a wider range of susceptibilities would probably be found.

For purposes of comparison, rats of the same age and stock as those used in the approximately lethal dose experiment on methyl iodide were injected subcutaneously with a solution of carbon tetrachloride in arachis oil over a range of doses from 0.33 to $2.4 \mathrm{~g}$. per $\mathrm{kg}$. All these animals survived the 24 hours after dosing; deaths from methyl iodide always occurred within this time. Given in this way methyl iodide would seem to be at least ten times as toxic as carbon tetrachloride.

Miller and Haggard (1943) found that the lethal intraperitoneal doses of methyl bromide were 0.12 to $0.18 \mathrm{~g}$. per $\mathrm{kg}$. The lethal subcutaneous dose of methyl iodide was $0 \cdot 15$ to $0.22 \mathrm{~g}$. per $\mathrm{kg}$., so the two compounds are in the same order of toxicity. Bachem (1927) found the iodide to be more toxic than the bromide. Von Oettingen (1937) states that " it appears that the toxicity of the monohalogenated hydrocarbons increases with the molecular weight ". 
Methyl iodide can produce the same type of vesicular burn as methyl bromide if it is closely applied to the skin, and therefore any clothing becoming contaminated should be removed immediately. When I allowed methyl iodide to evaporate freely from my skin no burns were produced, but the skin of others might be more sensitive. There is a considerable time lag between contact with the substance and the appearance of the lesions.

\section{Summary}

1. Methyl iodide should be regarded as at least as toxic as methyl bromide, and about ten times as toxic as carbon tetrachloride.

2. There is often a time lag between exposure to methyl iodide and the onset of symptoms.
3. Clothing contaminated with methyl iodide should be removed immediately to prevent blistering.

I should like to thank Dr. S. E. T. Kingman of the Joint Fire Research Organization of the Department of Scientific and Industrial Research for his interest in the work, the Iodide Education Bureau for the provision of methyl iodide, Dr. A. Marshall of the Bernhard Baron Institute of Pathology, the London Hospital, for examining and reporting on the histological sections, and Miss K. E. Kearney, Miss E. J. Fowler, and Miss J. Sheffield for technical assistance.

\section{REFERENCES} Bachem, C. (1927). Arch. exp. Path. Pharmak., 122, 69.
Ellis, O. C. de C. (1948). Nature, Lond., 161, 402. Garland, A., and Camps, F. E. (1945). British Journal of Industrial Medicine, 2, 209.

Jaquet, A. (1901). Dtsch. Arch. klin. Med., 71, 370.

Miller, D. P., and Haggard, H. W. (1943). J. Industr. Hyg., 25, 423. Miler, D. P., and Haggard, H. W. (1943), J.1.

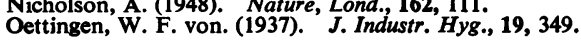

